\title{
INEQUALITIES FOR CONVEX FUNCTIONS AND DOUBLY STOCHASTIC MATRICES
}

\author{
MAREK NIEZGODA
}

Abstract. We generalize some results on convex functions presented in papers L. Bougoffa, New inequalities about convex functions, J. Inequal. Pure Appl. Math., 7 (4), (2006) Art. 148, and L.-C. Wang, X.-F. Ma and L.-H. Liu, A note on some new refinements of Jensen's inequality for convex functions, J. Inequal. Pure Appl. Math., 10 (2), (2009) Art. 48. To this end, we use majorization of vectors, doubly stochastic matrices and circular matrices.

Mathematics subject classification (2010): Primary 26D15, 26A51, Secondary 15A51.

Keywords and phrases: convex function, majorization, doubly stochastic matrix, circular matrix.

\section{REFERENCES}

[1] L. Bougoffa, New inequalities about convex functions, J. Inequal. Pure Appl. Math. 7, 4 (2006), Art. 148.

[2] S. S. Dragomir, A new refinement of Jensen's inequality in linear spaces, Math. Comput. Model. 52 (2010), 1497-1505.

[3] S. S. DRAGOMIR, A refinement of Jensen's inequality with applications for $f$-divergence measures, Taiwan. J. Math. 14, 1 (2010).

[4] L. HORVÁTH, A method to refine the discrete Jensen's inequality for convex and mid-convex functions, Math. Comput. Modelling 54 (2011), 2451-2459.

[5] L. Horváth And J. PeČArić, A refinement of the discrete Jensen's inequality, Math. Inequal. Appl. 14, 4 (2011), 777-791.

[6] A. W. Marshall, I. Olkin And B. C. ARnold, Inequalities: Theory of Majorization and Its Applications, Second Edition, Springer, New York, 2011.

[7] L.-C. WANG, X.-F. MA AND L.-H. LiU, A note on some new refinements of Jensen's inequality for convex functions, J. Inequal. Pure Appl. Math. 10, 2 (2009), Art. 48. 